\title{
Construção de capacidades político- relacionais para coordenação federativa no Programa Água para Todos: análise na perspectiva neoinstitucionalista
}

Dias Ramagem, Ricardo; Corrêa Gomes, Ricardo

Construção de capacidades político-relacionais para coordenação federativa no Programa Água para Todos: análise na perspectiva neoinstitucionalista

Administração Pública e Gestão Social, vol. 13, núm. 2, 2021

Universidade Federal de Viçosa, Brasil

Disponible en: http://www.redalyc.org/articulo.oa?id=351566014002

\section{(c) $(1) \Theta(9)$}

Esta obra está bajo una Licencia Creative Commons Atribución-NoComercial-SinDerivar 3.0 Internacional, 


\section{Construção de capacidades político-relacionais para coordenação federativa no Programa Água para Todos: análise na perspectiva neoinstitucionalista}

Political-relational capacity building for federative coordination in the Water for All Program: analysis from the neoinstitutionalist perspective

Desarrollo de capacidades político-relacionales para la coordinación federativa en el Programa Agua para Todos: análisis desde la perspectiva neoinstitucionalista

Ricardo Dias Ramagem

Programa de Pós-Graduação em Administração da

Universidade de Brasilia - PPGA/UnB., Brasil

ramagem.ricardo@gmail.com

Redalyc: http://www.redalyc.org/articulo.oa?

Ricardo Corrêa Gomes

Escola de Administração de Empresas da Fundação Getulio

Vargas - EAESP/FGV, Brasil

gomesric.rg@gmail.com

Recepción: 13 Octubre 2019

Aprobación: 24 Enero 2020

Publicación: 01 Abril 2021

\section{Resumo:}

Objetivo da pesquisa: Analisar as diferenças de trajetórias na construção de capacidades relacionais existentes nas duas principais organizações parceiras na execução do Programa Água para Todos (APT) e sua relação no arranjo institucional para a coordenação federativa.

Enquadramento teórico: Foi utilizada a abordagem teórica do neoinstitucionalismo histórico de forma a contribuir para o entendimento de como os arranjos institucionais de coordenação federativa se organizam e se relacionam na construção de capacidades político-relacionais em uma política pública de caráter complexo.

Metodologia: A pesquisa de natureza qualitativa utilizou fontes de dados como levantamento bibliográfico e documental, além da técnica da observação participante. Trata-se de um estudo de caso. Os dados obtidos foram analisados mediante a técnica da análise de conteúdo. As categorias analíticas utilizadas foram intersetorialidade, relações federativas, participação social e territorialidade. Resultados: O Ministério da Integração Nacional (MI) e o Ministério do Desenvolvimento Social e Combate à Fome (MDS) tiveram trajetórias de construção de capacidades relacionais diversas, conforme depreende-se da formação dos respectivos arranjos institucionais de coordenação federativa e na relação com a sociedade. Ao contrário do MI, ocorreu mudança institucional na política social a cargo do MDS, tendo como momento crítico a institucionalização do Sistema Único de Assistência Social (SUAS) com mecanismos de coordenação federativa e fluxo contínuo de recursos. Ocorreu policyfeedback positivo e de aprendizado na relação federativa e com a sociedade civil.

Originalidade: A análise da experiência nacional dos últimos vinte anos no tema da coordenação ainda apresenta lacunas. Considerar as distintas dimensões analíticas de forma conjunta permitiu compreender as especificidades de cada arranjo institucional e em que medida eles avançam em termos de coordenação de diferentes atores nos processos de tomada de decisão.

Contribuições teóricas e práticas: Este trabalho contribuiu para um melhor entendimento dos desafios da coordenação federativa de políticas públicas intersetoriais de combate à pobreza em ambiente institucional complexo. A pesquisa também agrega à base de conhecimento da literatura sobre arranjos institucionais ao trazer o estudo de caso de um programa ligado à Política Regional no Brasil, até então pouco estudada sob esta abordagem teórica.

PalaVras-ChaVE: Capacidades relacionais, Coordenação Federativa, Arranjos Institucionais, Programa Água para Todos.

\section{Abstract:}

Research objective: To analyze the differences in trajectories in the construction of relational capacities existing in the two main partner organizations in the execution of the Water for All Program (APT), and their relationship in the institutional arrangement for federative coordination. 
Theoretical framework: The theoretical approach of historical neoinstitutionalism was used in order to contribute to the understanding of how the institutional arrangements of federative coordination are organized and related in the construction of political-relational capacities in a complex public policy.

Methodology: The qualitative research used data sources such as bibliographic and documentary survey, in addition to the participant observation technique. This is a case study. The data obtained were analyzed using the content analysis technique. The analytical categories used were intersectoral, federative relations, social participation and territoriality.

Results: The Ministry of National Integration (MI) and the Ministry of Social Development and Fight against Hunger (MDS), had trajectories of building different relational capacities, as can be seen in the formation of the respective institutional arrangements for federative coordination and in relation to the society. Unlike the MI, there was an institutional change in social policy under the responsibility of the MDS, with the critical moment being the institutionalization of the Unified Social Assistance System (SUAS) with federative coordination mechanisms and a continuous flow of resources. Positive and learning policy feedback occurred in the federative relationship and with civil society.

Originality: The analysis of the national experience of the past twenty years on the topic of coordination still has gaps. Considering the different analytical dimensions together, it allowed us to understand the specifics of each institutional arrangement and the extent to which they advance in terms of coordinating different actors in the decision-making processes.

Theoretical and practical contributions: This work contributed to a better understanding of the challenges of federative coordination of intersectoral public policies to combat poverty in a complex institutional environment. The research also adds to the knowledge base of the literature on institutional arrangements by bringing the case study of a program linked to Regional Policy in Brazil, until then little studied under this theoretical approach.

Keywords: Relational capabilities, Federative Coordination, Institutional Arrangements, Water for All Program.

\section{ReSUMEN:}

Objetivo de la investigación: Analizar las diferencias en las trayectorias en la construcción de capacidades relacionales existentes en las dos principales organizaciones socias en la ejecución del Programa Agua para Todos (APT) y su relación en el arreglo institucional para la coordinación federativa.

Marco teórico: Se utilizó el enfoque teórico del neoinstitucionalismo histórico con el fin de contribuir a la comprensión de cómo los arreglos institucionales de coordinación federativa se organizan y relacionan en la construcción de capacidades políticorelacionales en una política pública compleja.

Metodología: La investigación cualitativa utilizó fuentes de datos como sondeo bibliográfico y documental, además de la técnica de observación participante. Este es un estudio de caso. Los datos obtenidos se analizaron mediante la técnica de análisis de contenido. Las categorías analíticas utilizadas fueron intersectorial, relaciones federativas, participación social y territorialidad.

Resultados: El Ministerio de Integración Nacional (MI) y el Ministerio de Desarrollo Social y Lucha contra el Hambre (MDS) tuvieron trayectorias de construcción de distintas capacidades relacionales, como se puede apreciar en la formación de los respectivos arreglos institucionales de coordinación federativa y en sociedad. A diferencia del MI, hubo un cambio institucional en la política social a cargo del MDS, siendo el momento crítico la institucionalización del Sistema Único de Asistencia Social (SUAS) con mecanismos de coordinación federativa y un flujo continuo de recursos. La retroalimentación positiva y de políticas de aprendizaje ocurrió en la relación federativa y con la sociedad civil.

Originalidad: El análisis de la experiencia nacional de los últimos veinte años en el tema de la coordinación aún tiene lagunas. Considerar las diferentes dimensiones analíticas en conjunto permitió comprender las particularidades de cada arreglo institucional y el grado en que avanzan en términos de articulación de diferentes actores en los procesos de toma de decisiones.

Aportes teóricos y prácticos: Este trabajo contribuyó a una mejor comprensión de los desafíos de la coordinación federativa de políticas públicas intersectoriales para combatir la pobreza en un entorno institucional complejo. La investigación también se suma a la base de conocimiento de la literatura sobre arreglos institucionales al traer el estudio de caso de un programa vinculado a la Política Regional en Brasil, hasta entonces poco estudiado bajo este enfoque teórico.

Palabras Clave: Capacidades relacionales, Coordinación Federativa, Arreglos Institucionales, Programa Agua para Todos.

\section{INTRODUÇÃO}

O ambiente institucional para a formulação, coordenação e execução de políticas no Brasil sofreu uma série de modificações nos últimos anos. A Constituição Federal de 1988 instituiu uma série de mecanismos para envolvimento dos atores sociais, políticos e econômicos no processo de formulação e gestão de políticas públicas ao ampliar os instrumentos de controle, participação e transparência nas decisões públicas. De acordo com Perez (2009), praticamente todas as atividades que a Constituição atribui à Administração 
Pública referentes às atividades de bem-estar essenciais devem ser executadas mediante a adoção de institutos participativos. Isto requer das burocracias governamentais, além de capacidade técnica-administrativa, altas capacidades de coordenação e execução para levar à consequência os objetivos pretendidos (Gomide \& Pires, 2014).

Soma-se a isso o fato de que um grande número de municípios brasileiros tem baixa capacidade institucional, dificuldades de ordem técnica, gerencial, financeira e mesmo de escala para o desempenho de suas competências. Situação semelhante é observada em alguns estados, em especial naqueles recémconstituídos, que também possuem baixa capacidade técnica e gerencial. Tanto nos casos de extensas aglomerações urbanas como nos pequenos e micromunicípios, os mecanismos de coordenação federativa e intersetorial são essenciais. Alguns temas da agenda dos governos também demandam trabalho cooperado e coordenado em sua implementação, como aqueles de responsabilidade partilhada, entre eles as políticas de desenvolvimento regional e urbano e as políticas sociais que funcionam de forma sistêmica (Cunha, 2004; Abrucio, 2005).

Desta forma, o desenvolvimento de capacidades estatais torna-se ainda mais importante levando-se em conta o ambiente institucional de maior complexidade, característico de um país em desenvolvimento, de grandes dimensões territoriais, de sistema federativo e com grande heterogeneidade e desigualdades regionais e sociais.

O modelo de federalismo cooperativo aproxima-se do proposto para a gestão das políticas sociais no texto constitucional, que define em seu art. 23 competências comuns para União, estados e municípios em importantes áreas como saúde, assistência social, educação e combate à pobreza, entre outras (Franzece \& Abrucio, 2009). Para atender aos pressupostos constitucionais cada área de política pública, foi preciso desenvolver mecanismos e arranjos institucionais que possibilitem a coordenação e cooperação intergovernamental. Todavia, observou-se um processo heterogêneo de gestão compartilhada, influenciado pela importância da temática na agenda governamental, pelo desenho de cada política específica e pela distribuição prévia de competências e do controle sobre os recursos entre as esferas de governo (Cavalcante, 2011; Arretche, 2012).

A construção institucional pode ser complexa quando requer ações em vários níveis subnacionais, em múltiplas arenas e com múltiplos atores. Isso fragmenta os processos políticos e permite que diferentes espaços de decisão se sobreponham e estejam conectados, muitas vezes de formas surpreendentes, quando se exige maior governança. Tais sobreposições e conexões, prevalentes no sistema político brasileiro, são problema comum em políticas públicas, especialmente em sistemas federativos e em políticas intersetoriais. Desta forma, em ambientes institucionais entrelaçados de tal maneira, um dos principais desafios para o funcionamento do governo passa pela busca por um nível mínimo de comunicação, articulação e coordenação entre os diversos atores envolvidos, e a produção de coerência e complementaridade entre suas ações (Abers \& Keck, 2013).

Neste contexto de complexidade, partindo-se do pressuposto de que não só capacidades técnicoadministrativas, mas também capacidades político-relacionais das burocracias são necessárias para a produção de políticas públicas que solicitam cooperação federativa e intersetorial e que o tema apresenta relevância acadêmica e política (Grin, Nascimento, Abrucio, \& Fernandes, 2018; Lotta \& Favareto, 2016; Pires \& Gomide, 2016; Matthews, 2012; Mann, 2008), este artigo tem por objetivo analisar as diferenças de trajetórias do processo de construção de capacidades relacionais existentes nas duas principais organizações parceiras e sua relação no arranjo institucional para a coordenação federativa do Programa Água para Todos. $\mathrm{O}$ artigo tem por finalidade contribuir para o debate sobre capacidades estatais necessárias para a coordenação federativa de políticas públicas em ambiente institucional complexo, ressaltando a importância dos pressupostos do neoinstitucionalismo histórico na compreensão desse fenômeno (Limongi, Almeida, \& Freitas, 2016; Pierson, 2004; Immergut, 1998; Hall \& Taylor, 1996; Thelen \& Steinmo, 1992). 
O trabalho está dividido em quatro partes, além desta introdução. A segunda seção trata do referencial teórico, que aborda a questão da capacidade do Estado na produção de políticas públicas, suas dimensões e sua relação com arranjos institucionais no contexto de coordenação federativa. A terceira seção apresenta aspectos da abordagem metodológica adotada. A quarta seção traz a descrição e análise do Programa Água para Todos, a atuação dos ministérios e a perspectiva de análise da dependência da trajetória no processo de atuação dos arranjos institucionais de articulação intergovernamental do programa analisado. Por fim, a quinta seção cuida das considerações finais do trabalho de pesquisa.

\section{CAPACIDADES POLÍTICO-RELACIONAIS, ARRANJOS INSTITUCIONAIS E COORDENAÇÃO FEDERATIVA}

A literatura sobre as capacidades do Estado é caracterizada por uma preocupação com as habilidades e competências do Estado de estabelecer seus objetivos e realizá-los. $\mathrm{O}$ conceito de capacidades estatais decorreu dos estudos das ciências sociais acerca do papel do Estado na promoção do desenvolvimento econômico. Atualmente, o conceito vem adquirindo centralidade nas análises sobre a efetividade do Estado ou "boa governança" (Matthews, 2012; Cingolani, 2013; Gomide 2016). Wu, Ramesh e Howlett (2015) procuram definir capacidades para produção de políticas públicas (policy capacity) como um conjunto de competências e recursos necessários para a execução de funções de políticas públicas. Portanto, capacidade estatal precisa ser abordada de maneira multidimensional (Cingolani, 2013; Grin, 2012).

De acordo com Cingolani (2013), o conceito de capacidades estatais pode ser disposto sob a forma de dimensões associadas às atividades exercidas pelo Estado. Segundo a autora, o termo "capacidade estatal" refere-se a uma ou a combinação das seguintes dimensões do poder do Estado: a) coercitivo e militar, b) fiscal, c) administrativo e de implementação, d) transformativo e de industrialização, e) relacional e de cobertura territorial, f) legal e g) político.

Grindle (1996), de forma mais concisa, destaca que o conceito possui quatro dimensões: a) capacidade administrativa: estrutura organizacional para executar funções essenciais e a prestação de serviços públicos, b) capacidade técnica: habilidades para formular e gerenciar políticas, c) capacidade institucional: definição de "regras do jogo" relativas à regulação econômica e comportamento político dos atores sociais, d) capacidade política: estabelecimento de canais legítimos e eficazes para lidar com demandas sociais.

Grin, Nascimento, Abrucio e Fernandes (2018) ressaltam que destas dimensões merecem destaque especial a capacidade política e institucional e capacidade administrativa e técnica na medida em que definem as possibilidades de poder infraestrutural descritas inicialmente por Michael Mann em 1984. Este autor considera que, para além do poder político clássico, exercido pelo governo numa situação de comandoobediência, existe uma espécie de poder infraestrutural, a capacidade de penetrar a sociedade e de organizar as relações sociais (Mann, 2008).

Percepção semelhante sobre as dimensões mais importantes é compartilhada por Pires e Gomide (2016) quando ressaltam que, a fim de conciliar as abordagens tradicionais sobre as capacidades estatais (dimensão administrativa) com as noções contemporâneas de governança, é necessário acrescentar a nova dimensão (relacional) dedicada à inclusão e interações entre os múltiplos atores nos processos de políticas públicas, de tal forma que as capacidades do Estado necessitem ser analisadas sob duas dimensões: i) técnico-administrativa, que envolve as capacidades derivadas da existência e funcionamento de burocracias competentes e profissionalizadas, dotadas dos recursos organizacionais, financeiros e tecnológicos necessários para conduzir as ações de governo de forma coordenada, e ii) político-relacional, associadas às habilidades de inclusão dos múltiplos atores (sociais, econômicos e políticos) de forma articulada nos processos de políticas públicas, visando à construção de consensos mínimos e coalizões de suporte aos planos, programas e projetos governamentais. Enquanto a primeira dimensão pode ser associada às noções de eficiência e eficácia, a segunda 
está relacionada com as ideias de legitimidade, aprendizagem e inovação nas ações dos governos, segundo os autores.

O significado de capacidade política e institucional, conforme Grin et al. (2018), ou capacidade políticorelacional, de acordo com Pires e Gomide (2016), coloca ênfase sobre a abordagem relacional, visando a compreender as conexões dentro do Estado Federativo e entre Estado e atores sociais, e, por essa razão, são chamadas de "capacidades geradoras de arranjos societais" (Kjaer, Hansen, \& Thomsen, 2002, p.21). O caráter relacional transcende as capacidades administrativas e burocráticas (Grin et al., 2018; Cingolani, 2013; Evans, 1995), daí a importância de arranjos institucionais mais participativos que possam expressar maior comprometimento com a legitimidade democrática, em termos de maior representatividade de interesses e de qualidade das decisões, possibilitando o aperfeiçoamento da política pública (Loureiro, Teixeira, \& Ferreira, 2014).

Desta forma, o conceito de arranjo institucional, conforme destacado por Gomide e Pires (2014, p. 19), é entendido como o "conjunto de regras, mecanismos e processos que definem a forma particular como se coordenam atores e interesses na implementação de uma política pública específica”. De acordo com os autores a análise de arranjos institucionais de políticas públicas consistiriam em uma chave para identificar e analisar a capacidade do Estado de implementar políticas públicas.

A literatura sobre os arranjos institucionais também aponta a dimensão das relações federativas como central para compreender a coordenação entre atores de diferentes entes federativos na promoção de políticas públicas. Essa variável é ainda mais central no caso de países com lógicas federativas tão complexas como o Brasil, no qual os entes têm diferentes responsabilidades sobre as políticas (Oliveira \& Lotta, 2017). Tanto a interdependência quanto a autonomia ocorrem em graus variados numa federação (Abrucio, 2005), fazendo com que as relações federativas se desdobrem em arranjos institucionais e movimentos cooperativos e competitivos entre os entes constituintes, o que torna a implementação de políticas sociais de combate à pobreza, como o Programa Água para Todos, um fenômeno complexo, que se desenvolve em diversas arenas e etapas, com o envolvimento de múltiplos atores e interesses.

Para o enfrentamento de problemas complexos o governo federal tem experimentado uma variedade de arranjos institucionais na tentativa de promover uma integração horizontal (entre setores de políticas públicas) e vertical (entre entes federativos) e de absorver de forma efetiva a participação social e a dimensão territorial em políticas públicas (Lotta \& Favareto, 2016). Uma dessas políticas prioritárias no período de 2011 a 2014 foi o Plano Brasil Sem Miséria (BSM), no qual se insere o Programa Água para Todos (APT).

Desta forma, quando o desenho da intersetorialidade de uma política social abarca os níveis locais, é de fundamental importância o tipo de instâncias de comunicação intergovernamental. A suposição é que quanto mais canais bidirecionais (dispositivos de governança comum entre níveis governamentais) que permitam a pactuação com os próprios níveis subnacionais e se inclinem a um modelo mais interativo de relações intergovernamentais, mais será favorecida a abordagem integral dos problemas (Cunill-Grau, 2014).

Os arranjos institucionais desempenham papel importante como limitadores ou facilitadores da ação intersetorial. Isso é especialmente essencial, no caso da intersetorialidade, não somente porque o ambiente institucional costuma incluir sistemas amplos de relações que cruzam distintas áreas jurisdicionais (Bryson, Crosby, \& Stone, 2006), mas porque os propósitos colaborativos, a estrutura e os resultados podem ser afetados pelo marco institucional de cada setor governamental, conforme observa Cunill-Grau (2014).

A abordagem teórica do neoinstitucionalismo, na sua vertente histórica, contribui para o entendimento do surgimento e do declínio de instituições, buscando suas origens, impactos e estabilidade ou instabilidade de instituições específicas, bem como configurações institucionais mais amplas. Para Thelen (1999) é relevante salientar que as instituições se modificam conforme o contexto, mas também são delimitadas por trajetórias passadas, o que solicita a necessidade de investigações com perspectiva temporal, ou seja, o ajustamento no tempo e a dependência da trajetória percorrida (path dependence) fazem a diferença na interpretação das transformações das instituições. O termo dependência da trajetória ou path dependence refere-se às escolhas 
do presente condicionadas pela herança institucional do passado. O conceito está relacionado à ideia de que acontecimentos do passado podem induzir a uma cadeia de determinações que influenciam as decisões políticas no presente (Thelen \& Steinmo, 1992; Pierson, 2004).

Uma ideia-chave para o conceito de path dependence é a noção de momento crítico (critical juncture). São circunstâncias decisivas na vida política, onde ocorrem transições que estabelecem certas direções de mudança e excluem outras num caminho que molda a política por anos. Referem-se ao momento de escolhas cruciais e seus legados. No neoinstitucionalismo histórico procura-se distinguir no fluxo dos eventos históricos os períodos de continuidade e os "momentos críticos", isto é, situações nas quais mudanças institucionais importantes se produzem, criando desse modo "bifurcações" que conduzem o desenvolvimento por um novo trajeto (Thelen \& Steinmo, 1992; Hall \& Taylor, 1996; Immergut, 1998; Pierson, 2004; Fernandes, 2013).

Outra noção importante para o conceito de dependência da trajetória é a de Retornos Crescentes (Increasing Returns). Significa que a probabilidade de obter benefícios relativos à permanência na trajetória atual cresce com o tempo, comparada com as alternativas possíveis, aumentando os custos de saída do caminho. Desta forma, os processos de retornos crescentes também podem ser identificados como de autorreforço ou como de feedback positivo (Pierson, 2004; Fernandes, 2013).

Todavia, conforme explicam Mahoney e Schensul (2006), é importante notar que ocorrem casos que não são sequências autorreforçantes e podem ser também incluídos como fator para a existência da dependência de trajetória. Estas situações podem ser chamadas de sequências reativas. São cadeias de eventos ordenados no tempo e conectados de forma causal. Cada evento na sequência é uma reação a um evento que ocorreu anteriormente e uma causa de eventos subsequentes. Ou seja, numa sequência reativa os eventos iniciais são também importantes, não porque desencadeiam um processo de autorreforço de um padrão, mas sim porque colocam em andamento uma cadeia de reações e contrarreações fortemente interligadas que conduz o processo a uma trajetória específica de desenvolvimento (Mahoney \& Schensul, 2006; Fernandes, 2013).

Observar como se desenvolveram os arranjos institucionais constituídos pelas organizações parceiras e respectivas capacidades político-relacionais, em um programa complexo de combate à pobreza de caráter federativo e intersetorial pode contribuir para um melhor entendimento dos desafios da coordenação de políticas em ambientes institucionais complexos.

\section{METODOLOGIA}

Os procedimentos metodológicos desta pesquisa enfocam a interação entre atores, políticas públicas e instituições, partindo do pressuposto de que as instituições afetam o comportamento dos atores e resultados das políticas. Tal dimensão pode ser apreendida pela análise sobre como os atores mobilizam as instituições em torno de uma política pública em cada contexto histórico. Sob o paradigma do neoinstitucionalismo histórico, discutimos como os arranjos institucionais de coordenação federativa se organizam e se relacionam com as políticas públicas, com base no estudo de caso do Programa Água para Todos (APT).

Segundo Yin (2014), o estudo de caso é útil quando as questões de interesse do estudo referem-se ao como e ao porquê, quando o pesquisador tem pouco controle sobre os acontecimentos e quando o foco se dirige a um fenômeno contemporâneo em um contexto natural. A presente análise é de natureza qualitativa, tendo como ponto de partida uma revisão bibliográfica sobre o tema do federalismo, relações intergovernamentais e políticas públicas de natureza intersetorial em ambiente institucional complexo.

Dessa forma, as principais fontes documentais relativas ao APT que contribuíram para a constituição das informações apresentadas são: regulamentos (leis, decretos, portarias), fontes jornalísticas, pesquisas e documentos técnicos. Dado que um dos autores atuou como servidor federal em uma das organizações envolvidas na gestão do programa, no período analisado de 2011 a 2014, a técnica da observação participante também constitui fonte importante das constatações discutidas. 
De acordo com Yin (2014), a observação participante consiste em uma das fontes de evidências e numa modalidade especial de observação na qual o pesquisador não é simplesmente um observador passivo. Em vez disso, ele pode assumir uma variedade de funções dentro de um estudo de caso e pode, de fato, participar dos eventos que estão sendo estudados. Trabalhar como membro de equipe em uma das organizações estudadas, por exemplo, permitiu ao pesquisador o acesso a informações derivadas da participação em reunióes e eventos relacionados ao estudo.

Os dados que emergiram a partir da observação participante referem-se a momentos específicos que permitem a compreensão histórica do trabalho de constituição dos arranjos institucionais referentes a uma das políticas estruturantes relacionadas a uma das organizações parceiras no APT, nas décadas de 2000 e 2010 , no caso a Política Nacional de Desenvolvimento Regional (PNDR), vinculada ao Ministério da Integração Nacional (MI). Como pode ser constatado no item 4.2, referente à análise dos arranjos institucionais de articulação federativa do MI, a observação participante, juntamente com outras fontes de dados, tornou mais abrangente a análise da intersetorialidade, relações federativas, participação social e aspectos territoriais referentes à atuação no âmbito do MI. Estes momentos específicos permitiram registros que se referem, por exemplo, às seguintes situações quanto às respectivas dimensões de análise:

Atuação da Câmara de Políticas de Integração Nacional e Desenvolvimento Regional - CPDR, referente à dimensão da intersetorialidade;

Atuação das superintendências de desenvolvimento regionais e da PNDR quanto à dimensão das relações federativas;

Os fóruns das mesorregiões, previstos pela PNDR, no âmbito da dimensão territorial;

$\mathrm{O}$ processo de instalação de cisternas de polietileno pelo MI, no aspecto da participação social.

Além dos registros oriundos da observação participante, ressalta-se que foram utilizadas, predominantemente, outras fontes de dados como regulamentos (leis, decretos, portarias), pesquisas e documentos técnicos.

Desta maneira, o processo de análise a que foram submetidas as referidas fontes de evidências, que permitiu chegar às considerações apresentadas, orientou-se pela análise de conteúdo conforme descrito por Miles e Huberman (1994) e por Bardin (2011). De acordo com os autores, a partir do momento em que a análise de conteúdo permite codificar o material coletado, deve produzir um sistema de categorias de análise.

As categorias utilizadas consistem em componentes que podem ser usados como elementos analíticos para a compreensão de arranjos institucionais de coordenação de políticas públicas existentes no âmbito do Programa Água para Todos. Referem-se às quatro dimensões que têm sido incorporadas, de diferentes maneiras, nos atuais arranjos institucionais, de acordo com as proposições de Lotta e Favareto (2016). São as seguintes: intersetorialidade, relações federativas, participação social e territorialidade.

A literatura nacional sobre o tema da coordenação, no entanto, aponta que a análise da experiência nacional dos últimos vinte anos no tema da coordenação ainda apresenta lacunas. Os avanços se deram de forma determinante, porém segmentada, ao olhar de maneira isolada dimensões analíticas como intersetorialidade, relações federativas, participação social e aspectos territoriais (Bronzo, 2010; Arretche, 2012; Pires \& Vaz, 2012; Favareto, 2012; Oliveira \& Lotta, 2017).

De acordo com Lotta e Favareto (2016), a análise dessas distintas dimensões analíticas de forma conjunta permite compreender as especificidades de cada arranjo institucional e em que medida eles avançam em termos de coordenação de diferentes atores nos processos de tomada de decisão.

Desta maneira, aqui serão consideradas estas dimensões por atenderem de forma mais adequada à situação do Programa Água para Todos, incorporando formas de coordenação com diversos tipos de atores envolvidos na produção desta política pública.

Ainda que o foco principal deste trabalho seja a compreensão de aspectos relacionados à coordenação federativa, considera-se que a análise das quatro dimensões de forma integrada confere maior clareza no 
entendimento do funcionamento do arranjo institucional e da construção de capacidades relacionais na produção da política pública.

A dimensão intersetorial, ou horizontal, considera a articulação entre diferentes setores nos processos de formulação, implementação e monitoramento das políticas. Como a primeira categoria analítica, a intersetorialidade refere-se à integração de diversos setores, visando à resolução de problemas sociais complexos cuja característica fundamental é a multicausalidade. São em geral problemas multidimensionais, multideterminados e com efeitos persistentes, tais como a pobreza e a desigualdade, e tem solicitado do poder público e da sociedade a defesa de abordagens intersetoriais de políticas públicas (Bichir, 2011). A intersetorialidade implica não somente que os diversos setores do governo entreguem a um mesmo público específico os serviços que são próprios de cada um, mas também, de maneira articulada entre si. A suposição é, portanto, que não basta a cada setor fazer o que lhe corresponde, de acordo com suas respectivas atribuições. Implica também que os setores entrem em um acordo para trabalhar conjuntamente visando a alcançar uma mudança social em relação à situação inicial (Bryson et al., 2006; Bronzo, 2010; Bichir, 2011; Cunill Grau, 2014; Veiga \& Bronzo, 2014; Lotta \& Favareto, 2016). De acordo com esses autores, ocorrem diferentes graus de materialização da intersetorialidade conforme a fase em que ela ocorre, se na formulação, implementação ou monitoramento da política. Estas subcategorias da intersetorialidade podem ser mais bem percebidas no quadro 1 .

A dimensão federativa, ou vertical, considera a incorporação das relações entre os diferentes entes subnacionais na tomada de decisão. Neste trabalho essa dimensão ganha maior centralidade. Esta segunda categoria analítica trata da forma como se estabelecem as relações federativas entre governo federal, governos estaduais e governos municipais. Procura analisar como os arranjos institucionais estabelecem a divisão de responsabilidades e de autonomia para a tomada de decisão, nas seguintes perspectivas analíticas: normatização (quem determina as regras e quem faz as leis), financiamento (como ocorre o financiamento do programa) e execução das políticas (quem executa e o alcance territorial da implementação) (Arretche, 2012). Essas podem indicar como diferentes formulações de arranjos institucionais podem levar a distintos graus de autonomia ou integração no federalismo brasileiro, conforme destacam Lotta e Favareto (2016), e constituem-se em subcategorias de análise conforme apresentado no quadro 1.

A terceira dimensão analítica diz respeito à ampliação da participação social na formulação e no controle das políticas, que, em conjunto com a transparência, reforça a necessidade do poder Executivo de se articular com outros atores (Gomide \& Pires, 2014). A dimensão da participação social incorpora diferentes atores não estatais nos processos decisórios. Busca compreender como os diversos atores sociais são considerados no processo de formulação, implementação e monitoramento de políticas públicas, que se constituem em subcategorias de análise conforme apresentado no quadro 1. A Constituição Federal de 1988 trouxe a participação como elemento fundamental para a democratização das políticas e o aumento de sua efetividade (Perez, 2009). Aliado a isso existe uma percepção de que amplas negociações e debates entre a pluralidade de atores envolvidos contribuem também para a legitimidade das políticas. A ocupação de espaços institucionalizados (como os conselhos e comitês) é uma maneira da sociedade intervir nas decisões públicas (Midlej, 2013). A participação pode ser entendida como parte do processo e do próprio conteúdo de uma renovada noção de desenvolvimento (Pires \& Vaz, 2014).

A quarta dimensão analítica refere-se à territorialidade, que procura verificar em que medida as políticas incorporam lógicas territoriais na sua concepção e implementação. Trata da relação das ações públicas com as peculiaridades do território foco da implementação. A abordagem territorial considera que fatores locais podem influenciar no resultado das ações realizadas na região. A literatura sobre o tema sugere a relação com três fatores da vida social local: (a) intermunicipalidade, ou seja, uma escala geográfica de planejamento das ações mais ampla do que os municípios e mais restrita dos que os estados, já que o tamanho reduzido e as limitadas capacidades institucionais de pequenos municípios torna-se um fator restritivo, daí a importância de verificar como a política lida com a dimensão territorial (Cunha, 2004; Favareto, 2012); (b) uma 
perspectiva intersetorial, capaz de articular interesses e capacidades coerentes com a diversidade das estruturas sociais locais, de forma a possibilitar a efetiva participação do poder público e da sociedade civil local nesses espaços, ou seja, observar se há novos espaços de participação territoriais previstos na política pública; (c) permeabilidade à participação de forças sociais preexistentes nos mecanismos de planejamento e gestão, ou seja, a construção de articulação, diálogo, integração com outras instâncias participativas já existentes nos territórios (Cunha, 2004; Favareto, 2012; OECD, 2013; Lotta \& Favareto, 2016). Estas perspectivas são sistematizadas no quadro 1 a seguir.

A utilização dessas dimensões de forma articulada enquanto um modelo analítico tem sido aplicada na análise de diferentes arranjos institucionais de políticas públicas nos três entes federativos em diversas áreas sociais e de infraestrutura (Sotero, Lotta, \& Oliveira, 2019). Este modelo analítico permite observar variáveis importantes para entender a definição dos atores envolvidos, como se efetiva a governança, os graus de autonomia e os processos decisórios (Lotta \& Favareto, 2016).

O quadro 1 traz uma descrição resumida das quatro categorias analíticas conforme modelo proposto por Lotta e Favareto (2016). 
Administração Pública e Gestão Social, 2021, vol. 13, núm. 2, Abril-Junio, ISSN: 2175-5787

Quadro 1: Categorias de Análise de arranjos institucionais

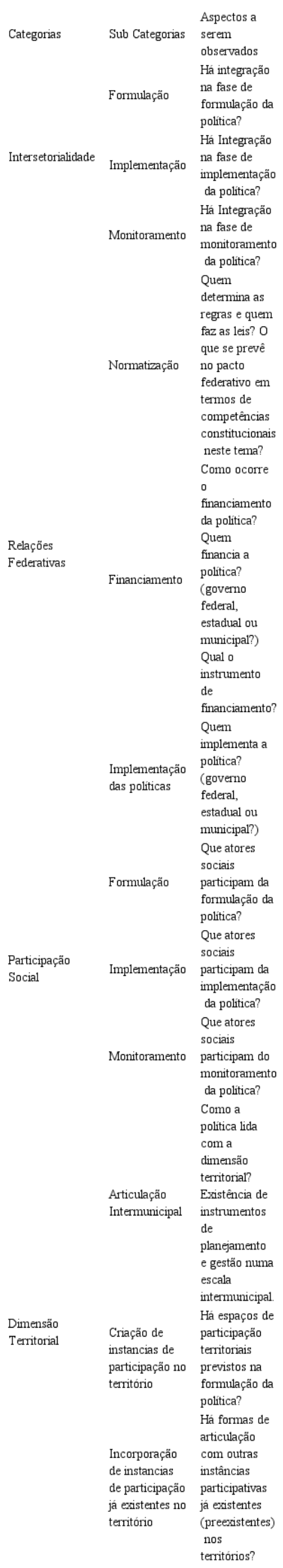


Fonte: Elaboração dos autores a partir de Lotta e Favareto (2016).

Conforme mencionado anteriormente a análise de arranjos institucionais de políticas públicas consistiriam em uma chave para identificar e analisar a capacidade do Estado de implementar políticas públicas. A ênfase sobre a abordagem relacional visa a compreender as conexóes dentro do Estado Federativo e entre Estado e atores sociais, e, por essa razão, são chamadas de capacidades geradoras de arranjos societais (Grin et al., 2018; Pires \& Gomide, 2016; Kjaer et al., 2002).

Desta forma, tendo como base o modelo analítico aqui apresentado, cabe trazer para melhor entendimento do assunto tratado neste trabalho a análise da trajetória do Programa Água para Todos com o auxílio da abordagem teórica do neoinstitucionalismo histórico, a ser tratada na próxima seção.

\section{O PROGRAMA ÁGUA PARA TODOS}

O Programa Água para Todos (APT) faz parte do Plano Brasil Sem Miséria (BSM), que teve maior protagonismo no período de 2011 a 2014. O BSM foi instituído pelo Decreto n. 7.492, de 2 de junho de 2011, com a finalidade de superar a situação de extrema pobreza da população em todo o território nacional, por meio da integração e articulação de políticas, programas e ações.

O BSM se propôs a ser um aprofundamento das medidas já desenvolvidas nos anos anteriores para combate à pobreza e para o desenvolvimento social do país. O plano estrutura cerca de 100 ações agregadas em três eixos - Garantia de Renda, Inclusão Produtiva e Acesso a Serviços Públicos. Embora a maioria dos programas vinculados ao BSM já existissem anteriormente, a inovação do plano foi unir esses programas em uma estratégia maior, dando a eles prioridade no processo de monitoramento constante, a fim de atingir a meta colocada pela Presidência da República de erradicar a extrema pobreza até 2014 (Decreto n. 7.492, 2011; Lotta \& Favareto, 2016).

Instituído pelo Decreto n. 7.535 de 26 de julho de 2011, o Programa Água para Todos (APT) foi concebido pelo Governo Federal a partir da necessidade de se universalizar o acesso e uso de água para populações carentes, residentes em comunidades rurais, principalmente no Semiárido nordestino (Decreto n. 7.535, 2011). O fornecimento de água de qualidade para o público beneficiado é realizado por meio da instalação dos seguintes equipamentos: a) cisternas de consumo, b) cisternas de produção, c) sistemas coletivos de abastecimento de água, d) kits de irrigação e e) pequenas barragens.

O Programa como está formulado atualmente surgiu em 2011, todavia, teve sua origem em articulações anteriores. Em novembro de 1999, durante encontro paralelo à Terceira Convenção de Combate à Desertificação e à Seca da Organização das Nações Unidas (ONU), um conjunto de organizações da sociedade civil elaborou o documento intitulado "Declaração do Semiárido", estabelecendo uma série de compromissos e ações pela sustentabilidade da vida no semiárido. O processo culminou na criação da Articulação no Semiárido Brasileiro (ASA) e na elaboração de uma proposta com vistas a garantir o acesso à água para consumo humano das famílias rurais do Semiárido por meio do armazenamento da água de chuva em cisternas familiares. A experiência prévia de utilização de cisternas para captação de água de chuva por iniciativa familiar e comunitária, com apoio de organizações de base, criou uma referência que inspirou outras experiências semelhantes e embasou a ASA na concepção do Programa de Formação e Mobilização Social para a Convivência com o Semiárido - Um Milhão de Cisternas (P1MC). A construção de cisternas, inicialmente realizada a partir de um convênio entre a ASA e o Ministério do Meio Ambiente (MMA) em 2001, permitiu desenvolver um projeto piloto para a construção de 500 cisternas. Posteriormente, o Ministério da Integração Nacional também estabeleceu parceria com a ASA, por meio da Companhia do Desenvolvimento dos Vales do São Francisco e do Parnaíba (CODEVASF). Em 2004, o Ministério do Desenvolvimento Social e Combate à Fome (MDS) instituiu a ação Construção de Cisternas 
para Armazenamento de Água no âmbito do Programa de Construção de Cisternas e Capacitação para Convivência com o Semiárido (Cadernos de Estudos Desenvolvimento Social em Debate, 2006).

Com o advento do Plano Brasil Sem Miséria em 2011, o governo federal concebeu a criação e reformulação de programas existentes, dentre os quais um programa que articulasse as ações de oferta de água para populações difusas em áreas carentes do meio rural, principalmente no semiárido, desenvolvidas há alguns anos por vários órgãos, principalmente o MDS, o MI e o MMA. Assim surgiu o Programa Água para Todos (O Brasil sem miséria, 2014).

Pelo governo federal as instituições e os atores envolvidos na execução do Programa Água para Todos são os seguintes órgãos da administração direta, além da cooperação de suas organizações vinculadas da administração indireta, do qual se destacam: 1) Ministério da Integração Nacional (MI); 2) Ministério do Desenvolvimento Social e Combate à Fome (MDS); 3) Ministério do Meio Ambiente (MMA); 4) Ministério das Cidades (MCidades); 5) Ministério da Saúde e Fundação Nacional das Águas (Funasa). Dentre esses órgãos se destacam em volume de ações, recursos e metas o MI e o MDS.

Governos estaduais e municipais também têm sua contribuição, todavia, vale destacar a participação social na atuação do programa por meio de um conjunto de organizações não governamentais (ONGs) associadas à Articulação no Semiárido Brasileiro (ASA).

O Ministério da Integração Nacional (MI) foi o responsável pela coordenação do comitê gestor do programa. Porém, a coordenação geral do Plano Brasil Sem Miséria coube ao Ministério do Desenvolvimento Social e Combate à Fome (MDS), juntamente com a Casa Civil da Presidência da República.

De acordo com classificação do Ministério do Planejamento, os órgãos do governo federal estão divididos em áreas de atuação compatíveis com campos organizacionais estabelecidos. No caso da política pública em análise, estão presentes as áreas sociais e de infraestrutura, onde estão alocadas as ações do MDS e do MI, respectivamente (Plano Plurianual [PPA] 2012-2015, 2011).

Esta distinção é importante na medida em que a forma de atuação de cada setor e os respectivos arranjos institucionais de coordenação federativa podem ter uma relação de sinergia ou de justaposição na execução do programa. Cabe, portanto, investigar como foram formados os respectivos arranjos institucionais de coordenação federativa do Ministério da Integração Nacional (MI) e do Ministério do Desenvolvimento Social e Combate à Fome (MDS). Estas questões são importantes na implementação de programas de natureza complexa como o Programa Água para Todos, que envolve a necessidade tanto da articulação intergovernamental quanto da intragovernamental.

Lício, Mesquita e Curralero (2011) destacam que questões de escala e fragmentação em diversos órgãos que não possuem políticas sistêmicas e instrumentos de coordenação nos três níveis de governo, prejudicam a própria articulação intersetorial. Estes aspectos de fragmentação e baixa capacidade de articulação federativa são corroboradas por Gomide e Pereira (2018) em relação ao setor de infraestrutura. Os autores argumentam que a profissionalização e a qualificação técnica existentes na burocracia pública do setor de infraestrutura do governo federal são constrangidas não só pela baixa autonomia e coesão intragovernamental como também as relações da burocracia com a sociedade local, os representantes dos entes federativos e as agências de controle são precárias. Tal situação constitui-se em uma barreira para a eficiência e legitimidade da ação estatal no setor.

A política estruturante das ações do MDS é a Política Nacional de Assistência Social (PNAS) organizada sob a forma do Sistema Único de Assistência Social (SUAS). No âmbito do MI a política orientadora das atividades de superação das desigualdades regionais, dentre as quais se insere o Programa Água para Todos, é a Política Nacional de Desenvolvimento Regional (PNDR). Essas políticas norteadoras das ações dos ministérios são os principais canais institucionais de relações intergovernamentais, podendo facilitar ou limitar a implementação de programas intersetoriais no território, como o APT. Na próxima seção serão analisados os arranjos institucionais de articulação federativa de cada uma dessas políticas e indicativos de sua relação na construção de capacidades político relacionais em cada setor de políticas. 


\subsection{Análise dos arranjos institucionais de articulação federativa do MDS}

A Constituição Federal de 1988 redefiniu tanto as bases do pacto federativo brasileiro quanto as diretrizes para as políticas sociais no país. Ela inovou ao institucionalizar uma agenda de políticas sociais com diretrizes de universalização e igualdade de acesso. Todavia, a Política de Assistência Social passa a ganhar concretude com a criação do Ministério do Desenvolvimento Social e Combate à Fome (MDS) em 2004, a aprovação da Política Nacional de Assistência Social (PNAS) também em 2004 e a institucionalização do Sistema Único de Assistência Social (SUAS) em 2005, estabelecendo mecanismos institucionalizados de relações intergovernamentais para a coordenação federativa e garantindo o fluxo contínuo de recursos por meio do Fundo Nacional de Assistência Social (FNAS) (O Brasil sem miséria, 2014).

Estes eventos se caracterizam como momentos críticos que demarcaram a mudança institucional na política nacional de assistência social, conforme a abordagem do neoinstitucionalismo histórico (Thelen \& Steinmo, 1992; Pierson, 2004). Neste caso, com o estabelecimento deste novo arranjo institucional, foram criadas as condições para a construção de capacidades político-relacionais no setor de políticas sociais, fortalecendo as relações federativas e a capacidade institucional, historicamente baixa, de municípios na gestão da assistência social com repercussão positiva na mobilização social para a construção de cisternas do Programa Água para Todos em municípios do Semiárido, ocorrendo um policy feedback (retroalimentação de políticas) positivo e de aprendizado (Pierson, 2004; Grin, 2014; Fernandes \& Araújo, 2015; O Brasil sem miséria, 2014).

No caso do MDS a institucionalidade das relações intergovernamentais articulada pela PNAS e pelo SUAS contribui para a efetividade da interlocução federativa do BSM e dos programas nele incluídos, como o APT, na medida em que os governos subnacionais, principalmente os governos locais (municipais) adquirem centralidade no processo. Um dos motivos para a centralidade dos municípios é o Cadastro Único, porta de entrada para o BSM, pois o responsável pelo registro das famílias no Cadastro é o poder público municipal. O município também tem papel de destaque no funcionamento da rede de assistência social, a grande referência para as famílias beneficiárias do programa (O Brasil sem miséria, 2014; Lotta \& Favareto, 2016).

$\mathrm{Na}$ dimensão intersetorial, os arranjos de implementação variam de acordo com o órgão executor da ação. Todavia, vale destacar a contribuição no papel de convergência realizada pela utilização do Cadastro Único na identificação do público-alvo de forma a conferir alguma integração entre as organizações. A etapa que teve maior grau de intersetorialidade foi a de monitoramento, por intermédio das reuniões do Grupo Interministerial de Acompanhamento e das salas de situação criadas no BSM liderado pelo MDS.

Outra contribuição importante resulta na atividade denominada Busca Ativa, que comporta a identificação no território de pessoas em situação de vulnerabilidade e risco social com violação de direitos para a viabilização do acesso a serviços socioassistenciais. A Busca Ativa é uma ação que faz parte da função de Vigilância Social prevista na PNAS. As informações coletadas no território servem para subsidiar um melhor planejamento das ações da assistência social e identificação de famílias a serem atendidas (O Brasil sem miséria, 2014). Neste processo destacam-se a capacidade da PNAS de estabelecer dois princípios importantes também por meio de outros programas (PAIF - Proteção e Atendimento Integral à Família) e estruturas de apoio (CRAS - Centros de Referência da Assistência Social): a territorialização e a chamada matricialidade sociofamiliar, buscando a centralidade na família e no território de forma institucionalizada, com repercussão na integração com outras instâncias participativas já existentes no território (Jaccoud, 2019).

A capacidade relacional ou a interação entre as burocracias do setor social e atores locais ganha reforço com o processo de construção de cisternas de placas, que confere maior participação social. Resultado de um processo social de aprendizado sobre os meios de convivência com a seca, a cisterna de placas de alvenaria para captação e armazenamento de água de chuva são de fácil aplicação e apropriação pela comunidade. $\mathrm{Na}$ implantação da tecnologia, a mão de obra geralmente é local, sendo que os próprios beneficiários são treinados 
para a construção da estrutura (O Brasil sem miséria, 2014). A síntese da análise do arranjo institucional de articulação do MDS é apresentada no quadro 2.

Quadro 2: Síntese da análise do arranjo institucional de articulação do MDS no APT

\begin{tabular}{|c|c|}
\hline \multicolumn{2}{|c|}{$\begin{array}{l}\text { Arranjo institucional de articulação do } \\
\text { MDS (PNAS) }\end{array}$} \\
\hline Intersetorialidade & $\begin{array}{l}\text { Relaçōes } \\
\text { Federativas }\end{array}$ \\
\hline $\begin{array}{l}\text { Arranjos variam } \\
\text { de acordo com o } \\
\text { órgäo executor. } \\
\text { Utilização do } \\
\text { Cadastro Único } \\
\text { trouxe alguma } \\
\text { integração entre } \\
\text { as organizações } \\
\text { No } \\
\text { monitoramento } \\
\text { ocorreu maior } \\
\text { intersetorialidade } \\
\text { - salas de } \\
\text { situação do BSM }\end{array}$ & $\begin{array}{l}\text { PNAS e SUAS } \\
\text { contribuiram } \\
\text { para a efetividade } \\
\text { da interlocuçäo } \\
\text { federativa do } \\
\text { BSM e do APT } \\
\text { Seguido por } \\
\text { rápido } \\
\text { incremento das } \\
\text { capacidades } \\
\text { estatais dos entes } \\
\text { federativos }\end{array}$ \\
\hline $\begin{array}{l}\text { Participação } \\
\text { Social } \\
\text { Conhecimento } \\
\text { local e } \\
\text { participação das } \\
\text { comunidades na } \\
\text { construção das } \\
\text { cisternas de } \\
\text { placa (concreto). } \\
\text { Capacitação das } \\
\text { comunidades e } \\
\text { uso de mão de } \\
\text { obra local. A } \\
\text { capacidade } \\
\text { relacional e a } \\
\text { interação entre as } \\
\text { burocracias do } \\
\text { setor social e } \\
\text { atores locais } \\
\text { aumentam com o } \\
\text { processo de } \\
\text { construção de } \\
\text { cisternas de } \\
\text { placas. }\end{array}$ & $\begin{array}{l}\text { Dimensão } \\
\text { Territorial } \\
\text { Cadastro Único e } \\
\text { a Busca Ativa } \\
\text { tem papel } \\
\text { fundamental para } \\
\text { necessidades de } \\
\text { cada familia e } \\
\text { identificá-las no } \\
\text { território } \\
\text { Capacidade da } \\
\text { PNAS de } \\
\text { estabelecer } \\
\text { princípios e } \\
\text { estruturas } \\
\text { importantes } \\
\text { (CRAS - Centros } \\
\text { de Referência da } \\
\text { Assistência } \\
\text { Social), } \\
\text { buscando a } \\
\text { centralidade na } \\
\text { familia e no } \\
\text { território. }\end{array}$ \\
\hline
\end{tabular}

Fonte: Elaborado pelos autores.

\subsection{Análise dos arranjos institucionais de articulação federativa do MI}

No ambiente organizacional do Ministério da Integração Nacional (MI) predomina a ótica do setor de infraestrutura, na medida em que a área de maior expressão e objeto de atenção política e econômica refere-se à infraestrutura hídrica. Dela fazem parte a Secretaria de Infraestrutura Hídrica, a Secretaria de Irrigação, uma empresa estatal, a Companhia do Desenvolvimento dos Vales do São Francisco e do Parnaíba (CODEVASF) 
e uma autarquia, o Departamento Nacional de Obras Contra as Secas (DNOCS). Mesmo que o Programa Água para Todos, no âmbito do MI, seja coordenado pela Secretaria de Desenvolvimento Regional, a lógica de atuação predominante no programa recebe forte influência da CODEVASF, na condição de organização mais estruturada, de maior capilaridade e principal executora do APT no âmbito do Ministério da Integração Nacional.

Cabe à Secretaria de Desenvolvimento Regional (SDR/MI) a formulação, implementação, monitoramento e avaliação das ações do APT. A política estruturante que procura guiar as ações do MI e da SDRé a Política Nacional de Desenvolvimento Regional (PNDR), instituída pelo Decreto n. 6.047, de 22 de fevereiro de 2007. Após o advento do BSM, com a inclusão do APT no seu rol de programas, este passa a ter maior expressão política e ganha destaque na interlocução entre os ministérios responsáveis pela superação da desigualdade social (MDS) e regional (MI) no governo federal.

Apesar de todo esforço de articulação realizado pelo BSM, percebe-se que ocorrem lacunas em alguns territórios e justaposição em outros, além da sinergia desejável entre as ações do MI e MDS, não só por problemas inerentes às dificuldades de articulação intersetorial, mas também pela dimensão territorial. Mesmo com a criação de comitês intersetoriais na etapa de formulação, persistiu a lógica setorial na implementação. Neste ponto entra uma importante interface necessária entre a política regional e a política social. Caso característico da questão da territorialidade das ações refere-se à distribuição mais adequada dos equipamentos de oferta de água por município ou microrregião. Cabe ressaltar a histórica dificuldade de interlocução federativa, caracterizando uma dependência da trajetória negativa no âmbito do Ministério da Integração Nacional e suas coligadas. O termo dependência da trajetória ou path dependence refere-se às escolhas do presente condicionadas pela herança institucional do passado. O conceito está relacionado à ideia de que acontecimentos do passado podem induzir a uma cadeia de determinações que influenciam as decisões políticas no presente (Thelen \& Steinmo, 1992; Pierson, 2004).

$\mathrm{Na}$ análise dos arranjos institucionais de articulação do MI foi possível contar também com a técnica da observação participante, conforme mencionado na metodologia deste trabalho (Yin, 2014). Os dados que surgiram a partir da observação participante, que também são corroborados por outras fontes de dados como regulamentos, pesquisas e documentos técnicos, permitiram a compreensão histórica do trabalho de constituição dos arranjos institucionais referentes à Política Nacional de Desenvolvimento Regional (PNDR) e ao funcionamento da estrutura organizacional e de alguns programas vinculadas ao Ministério da Integração Nacional (MI). Trabalhar como membro de equipe neste ambiente organizacional permitiu ao pesquisador o acesso a informações derivadas da participação em reuniões e eventos relacionados ao estudo, de forma a trazer maior compreensão na análise da intersetorialidade, relações federativas, participação social e aspectos territoriais referentes à atuação no âmbito do MI. Estes momentos específicos permitiram registros que se referem aos aspectos mencionados a seguir quanto às respectivas dimensões de análise.

No passado, relativamente recente, existiram tentativas de construção de arenas ou fóruns de negociação intersetorial e coordenação federativa referente a políticas regionais. As instâncias de coordenação e articulação da PNDR foram a Câmara de Políticas de Integração Nacional e Desenvolvimento Regional (criada em 2003) no nível nacional; as superintendências de desenvolvimento regionais SUDENE, SUDAM e SUDECO no nível regional e os fóruns do Programa das mesorregiões diferenciadas (PROMESO) no nível local. No entanto este arranjo institucional mostrou-se insuficiente (Alves \& Rocha, 2014; Política Nacional de Desenvolvimento Regional, 2011).

Entre 2007 e 2010 a ação da Câmara arrefeceu, tanto assim que o relato de funcionamento do principal grupo de trabalho o GTI-PDR vai até 24 de novembro de 2006. Quanto à atuação das superintendências de desenvolvimento regionais SUDENE, SUDAM e SUDECO, vale mencionar que a despeito da recriação formal, as superintendências permaneceram à espera de reformas estruturais que lhes permitissem atuar com efetividade, uma vez que seus quadros de pessoal encontram-se defasados, mal aparelhados e carentes de orientação estratégica. Os riscos de captura por interesses partidários permaneceram latentes no órgão, 
demonstrando a persistência das práticas clientelistas (Acórdão n. 2.919-Plenário, 2009; Política Nacional de Desenvolvimento Regional, 2011;; Karam, 2012).

Os fóruns das mesorregiões diferenciadas, no nível local, mesmo com todo o esforço empreendido, apresentavam enormes fragilidades institucionais. Não eram instâncias com respaldo normativo-legal. Contavam apenas com poucos recursos para mobilização e por vezes eram atropelados por decisões tomadas "de cima", sem respaldo dos componentes do fórum, além da captura por grupos pouco representativos da sociedade local (Política Nacional de Desenvolvimento Regional, 2011).

No período de 2012 a 2013 o MI procurou superar tais obstáculos propondo uma nova política, a PNDR II, a partir de um debate com participação de diferentes segmentos da sociedade envolvendo cerca de 13 mil pessoas em um processo conferencial, que resultou na definição de princípios e diretrizes com o intuito de superar os gargalos relacionados, especialmente, à fragilidade da governança para uma implementação coordenada e ao fortalecimento de instrumentos de financiamento do desenvolvimento regional, conforme destacado por Alves e Rocha (2014). As deliberações resultantes do processo serviram de subsídio para a elaboração de Projeto de Lei encaminhado ao Congresso Nacional. O processo de construção da PNDR II ainda está inconcluso, portanto, não podendo ser caracterizado até o momento como uma mudança institucional de fato.

Além destas lacunas, o MI não desenvolveu mecanismos efetivos de interlocução federativa com as unidades subnacionais. Não estimulou a criação de conselhos ou fóruns de secretários estaduais de assuntos de desenvolvimento regional. Ao contrário de outras políticas públicas transversais ou setoriais, o tema do desenvolvimento regional não constituiu canais institucionalizados de diálogo federativo (Coêlho, 2017; Karam, 2012; Política Nacional de Desenvolvimento Regional, 2011), fragilizando a perspectiva de formação de capacidades relacionais entre as burocracias federais, estaduais e municipais. Na relação com a sociedade civil o MI priorizou a instalação de cisternas de polietileno (um tipo de plástico) por meio de empresas privadas contratadas, cujo processo não envolve a coparticipação das famílias beneficiárias e atores sociais locais, negligenciando a formação de aprendizado e a utilização de mão de obra local. Estes aspectos corroboram as observações de Gomide e Pereira (2018) a respeito das dificuldades de capacidades relacionais do setor de infraestrutura no Brasil contemporâneo. A síntese da análise do arranjo institucional de articulação do MI é apresentada no quadro 3. 
Ricardo Dias Ramagem, et al. Construção de capacidades político-relacionais para coordenaÇão feder...

Quadro 3: Síntese da análise do arranjo institucional de articulação do MI no APT

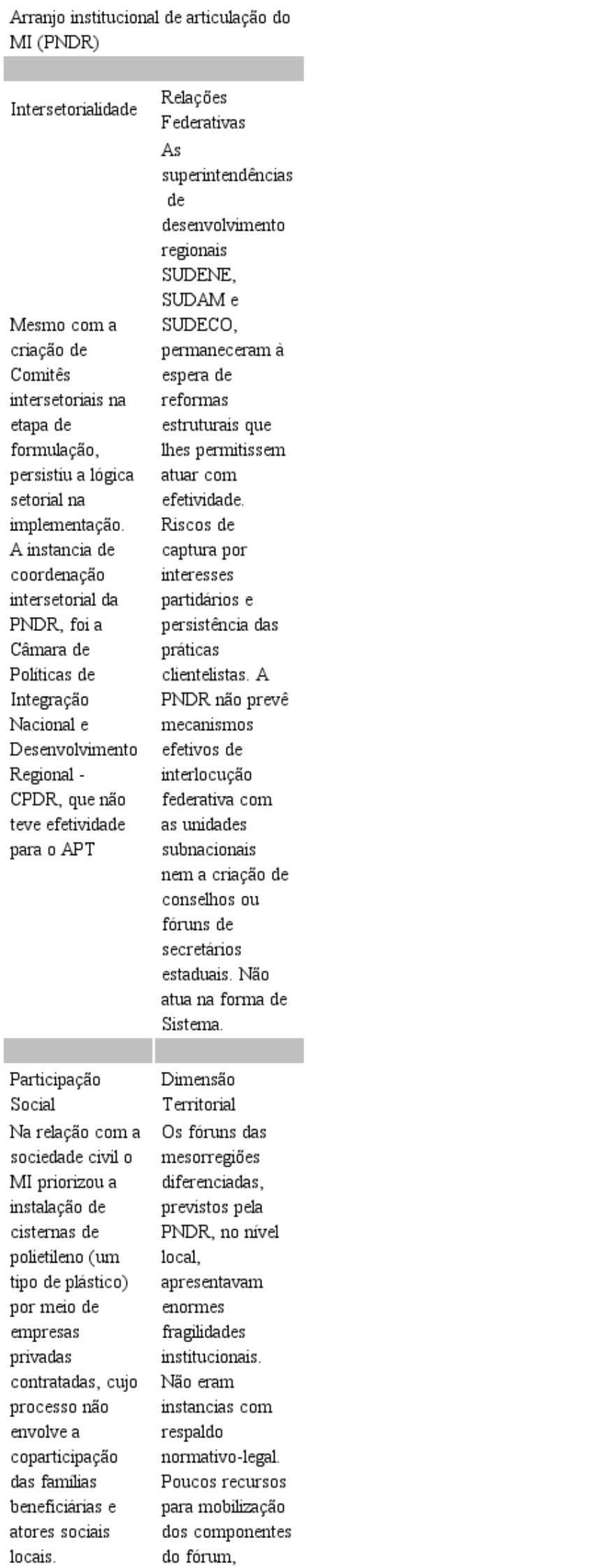


Fonte: Elaborado pelos autores.

\section{CONSIDERAÇÕES FINAIS}

Esta pesquisa teve como objetivo compreender as diferenças de trajetórias na construção de capacidades relacionais existentes nas duas principais organizações parceiras na execução do Programa Água para Todos (APT), e sua relação no arranjo institucional para a coordenação federativa sob a ótica do neoinstitucionalismo histórico. O Ministério da Integração Nacional (MI) e o Ministério do Desenvolvimento Social e Combate à Fome (MDS), pertencentes a setores de políticas públicas diferentes (o de infraestrutura e o social) tiveram trajetórias distintas de formação de arranjos institucionais nas suas políticas estruturantes com repercussão nos canais de comunicação e relações intergovernamentais e com a sociedade civil na execução do programa.

Nesta pesquisa mostrou-se que ocorreu mudança institucional significativa na política social implementada pelo MDS, tendo como momento crítico a institucionalização do Sistema Único de Assistência Social (SUAS) em 2005, estabelecendo mecanismos institucionalizados de coordenação federativa e garantindo o fluxo contínuo de recursos por meio do Fundo Nacional de Assistência Social (FNSA), estimulando a adesão das unidades subnacionais. Ocorreu um policyfeedback positivo e de aprendizado na relação federativa com municípios e com a sociedade civil. Esta conjunção de fatores positivos na configuração de arranjos institucionais e capacidades relacionais não ocorreu com o MI. O ministério não construiu uma articulação federativa sistêmica e eficaz. Os canais de interlocução com a sociedade civil não tiveram a intensidade e a representatividade necessárias, que conferissem maior legitimidade ao processo. Apesar da estratégia de repasse de recursos no APT ser semelhante (transferências voluntárias por meio de convênios ou termos de parceria), a forma de construção de capacidades relacionais é bastante diversa, seja na relação federativa, seja na relação com a sociedade e no aprendizado das famílias beneficiárias expresso na construção compartilhada da cisterna de placa (MDS) ou na simples recepção da cisterna de polietileno (MI).

Este trabalho contribuiu para um melhor entendimento dos desafios da coordenação federativa de políticas públicas intersetoriais de combate à pobreza em ambiente institucional complexo característico de um país em desenvolvimento, de grandes dimensões territoriais, de sistema federativo e com grande heterogeneidade e desigualdades regionais e sociais. $\mathrm{O}$ trabalho mostrou que a articulação intersetorial pode sofrer limitações quando uma organização parceira carece de instrumentos e canais institucionais efetivos de relações intergovernamentais dificultando a construção de capacidades estatais no território e junto a sociedade civil. Ou seja, a fragilidade do arranjo institucional do MI (e da PNDR) traz reflexos negativos junto aos programas a ele vinculados como o APT. A pesquisa também agrega à base de conhecimento da literatura sobre arranjos institucionais ao trazer o estudo de caso de um programa ligado à Política Regional no Brasil, até então pouco estudada sob esta abordagem teórica.

Compreender o desenvolvimento dos arranjos institucionais e da trajetória de mudança institucional nas políticas de suporte a um programa intersetorial de oferta de água no contexto de combate à pobreza como fenômenos complexos permite uma análise mais aprofundada tanto dos processos de mudança como das reações, entraves e limites à sua implementação. Identificar os limites impostos e as estratégias implementadas ao longo da institucionalização de políticas públicas de combate à pobreza pode ser um caminho necessário para garantir sua continuidade e enfrentamento aos pontos de entrave e integração institucional.

Como agenda de pesquisa, sugere-se ampliar a análise, incorporando inclusive o período mais recente, em que se verifica desmobilização do processo relativo às políticas de oferta de água às populações do Semiárido. Por sua vez, a análise e avaliação das iniciativas implementadas também constituem oportunidade de aprofundar a pesquisa, inclusive com a compreensão dos mecanismos que afetam os instrumentos de coordenação federativa de organizações que não atuam sob a forma de sistema. 
Por fim, as considerações aqui expressas não pretendem esgotar o tema abordado. São sinais indicativos na busca de maior detalhamento. Novas pesquisas merecem ser realizadas, como as que identifiquem o papel dos stakeholders envolvidos, assim como uma análise detalhada das categorias ou variáveis de arranjos institucionais e da dimensão relacional das capacidades estatais envolvidas, na medida em que a capacidade relacional, referente ao processo de interação qualificada entre os múltiplos atores interessados, estaria positivamente associada ao aprendizado social e apoio político aos programas, resultando em serviços públicos de qualidade e com os benefícios esperados junto à sociedade. Neste campo, de recente inserção tanto na agenda pública como na análise de políticas públicas, há muito que se investigar e que contribuir, na expectativa de construção de uma sociedade mais justa e com políticas públicas que conduzam à equidade e redução das desigualdades regionais e sociais.

\section{REFERENNCIAS}

Abers, R. N., Keck, M. E. (2013). Practical Authority: Agency and Institutional Change in Brazilian Water Politics. Oxford: Oxford University Press.

Abrucio, F. L. (2005). A coordenação federativa no Brasil: a experiência do período FHC e os desafios do governo Lula. Revista de Sociologia e Politica, 24, 41-67.

Acórdão n. 2.919-Plenário, de 02 de dezembro de 2009. Diário Oficial da União, Brasília, DF, 04 dez.

Alves, A. M.,Rocha, J. M. Neto (2014). A nova Política de Desenvolvimento Regional - PNDR II. Revista Politica e Planejamento Regional, 1(2), 311-338.

Arretche, M. (2012). Democracia, federalismo e centralização no Brasil. 1. ed. Rio de Janeiro: Ed. Fundação Getúlio Vargas/Fiocruz.

Bardin, L. (2011). Análise de Conteúdo. São Paulo: Edições 70.

Bichir, R. M. (2011). Mecanismos federais de coordenação de politicas sociais e capacidades institucionais locais: o caso do Programa Bolsa Familia.278 p. Tese (Doutorado em Ciência Política) - Instituto de Estudos Sociais e Políticos, Universidade Estadual do Rio de Janeiro, Rio de Janeiro.

Bronzo, C. (2010). Intersetorialidade, autonomia e território em programas municipais de enfrentamento da pobreza: experiências de Belo Horizonte e São Paulo. Planejamento e Políticas Públicas, (35), 119-159.

Bryson, J. M., Crosby, B., Stone, M. M. (2006). The design and implementation of Cross-Sector Collaborations: propositions from the literature. Public Administration Review, 66(1), 44-55.

Cavalcante, P. (2011). Descentralização de políticas públicas sob a ótica neoinstitucional. Revista de Administração Pública, 45(6), 1781-1804.

Cingolani, L. (2013). The State of State Capacity: A review of concepts, evidence and measures. UNU-MERIT Working Paper Series on Institutions and Economic Growth, IPD WP13. \#2013-053.

Coêlho, V. L. P. (2017). A PNDR e a nova fronteira do desenvolvimento regional brasileiro. Boletim regional, urbano e ambiental - IPEA/Dirur - 17 (dez. 2017) - Brasília, DF.

Cunha, R. E. (2004). Federalismo e relações intergovernamentais: os consórcios públicos como instrumento de cooperação federativa. Brasília: Revista do Serviço Público 55(3), 5-36.

Cunill-Grau, N. (2014). La intersectorialidad en las nuevas políticas sociales: un acercamiento analítico-conceptual. Gestión y política pública, 23(1), 5-46.

Decreto n. 7.492, de 2 de junho de 2011, que institui o Plano Brasil Sem Miséria. Brasília: Imp. Oficial.

Decreto n. 7.535, de 2011, que institui o Programa Água para Todos. Brasília.

Evans, P. (1995). Embedded autonomy: States and industrial transformation. Princeton, USA: Princeton University Press.

Favareto, A. (2012). As políticas de desenvolvimento territorial rural no Brasil em perspectiva - uma década de experimentações. Desenvolvimento em Debate (INCT/PPED), 1(1), 47-63. 
Fernandes, A. S. A. (2013). Dependência de trajetória e mudança institucional. Perspectivas: Revista de Ciências Sociais, 44(1), 177-192.

Fernandes, A. S. A., Araújo, S. M. V. G. (2015). A criação de municípios e a formalização de regiões metropolitanas: os desafios da coordenação federativa. Revista Brasileira de Gestão Urbana (Brazilian Journal of Urban Management), 7(3), 295-309.

Franzese, C., Abrucio, F. (2009). A combinação entre federalismo e as políticas públicas no pós-1988: os resultados nas áreas de saúde, assistência social e educação. In: Rocha, M.C.G. da (Org.). Reflexõespara ibero-América: avaliação de programas sociais. Brasília: Enap, 25-42.

Gomide, A., Pereira, A. (2018). Capacidades estatais para políticas de infraestrutura no Brasil contemporâneo. Revista de Administração Pública, 52(5), 935-955.

Gomide, A., Pires, R. (2014). Capacidades estatais e democracia: a abordagem dos arranjos institucionais para análise de políticas públicas. In Gomide, A., Pires, R. (Org.). Capacidades Estatais e Democracia: Arranjos Institucionais de Politicas Públicas. Brasília, DF: IPEA.

Gomide, A. (2016). Capacidades estatais para políticas públicas em países emergentes: (des)vantagens comparativas do Brasil. In Gomide, A. Boschi, R. (Orgs.). Capacidades estatais em paises emergentes: o Brasil em perspectiva comparada - Rio de Janeiro, RJ: Ipea.

Grin, E. J. (2012). Notas sobre a construção do conceito de capacidades estatais. Revista Teoria \& Sociedade, 20(1), $148-176$.

Grin, E. J. (2014). Trajetória e avaliação dos programas federais brasileiros voltados a promover a eficiência administrativa e fiscal dos municípios. Revista de Administração Pública, 48(2), 459-480.

Grin, E. J, Nascimento, B. A., Abrucio, F. L., Fernandes, A. S. A. (2018). Desconexões e hiatos: uma análise de capacidades estatais e finanças públicas em municípios brasileiros. Cadernos Gestão Pública e Cidadania, 23(76), 312-336.

Grindle, M. S. (1996). Challenging the state: Crisis and innovation in Latin America and Africa. Cambridge, USA: Cambridge University Press.

Hall, P., \& Taylor, R. (1996). Political Science and The Three New Institutionalisms. In: Political Studies 44, p. 936-957.

Immergut, E. (1998). The theoretical core of the new institutionalism. Politics and Society, 26(1), 5-34.

Jaccoud, L. (2019). Coordenação intergovernamental e territórios no SUAS: o caso do Paif. In: Lotta, G. (org.). Teoria e análises sobre implantação de políticas públicas no Brasil. Enap, Brasília, DF. 324 p.

Karam, R. A. S. (2012). A questão regional brasileira no século XXI: um olhar sobre o dissenso. Revista Inclusão Social, 6(1), 33-51.

Kjær, M., Hansen, O. H., Thomsen, J. P. F. (2002). Conceptualizing State Capacity. In Research Report No. 6, Demstar: Department of Political Science, University of Aarhus.

Lício, E. C., Mesquista, C. S., Curralero, C. R. C. (2011). Desafios para a coordenação intergovernamental do Programa Bolsa Família. Revista de Administração de Empresas, 51(5), 458-470.

Limongi, F., Almeida, M. H. T., Freitas, A. (2016). Da sociologia política ao (neo) institucionalismo: trinta anos que mudaram a ciência política no brasil. In Avritzer, L., Milani, C., Braga, M. S. (org.). A ciência política no Brasil: 1960-2015. Ed. FGV, 468p.

Lotta, G., Favareto, A. (2016). Desafios da integração nos novos arranjos institucionais de políticas públicas no Brasil. Revista de Sociologia e Política, 24(57), 49-65.

Loureiro, M. R., Teixeira, M. A. C., Ferreira, A. (2014). Conflitos e articulação de interesses no Projeto de Integração do rio São Francisco. In Gomide, A. Pires R. (Org.). Capacidades Estatais e Democracia: Arranjos Institucionais de Políticas Públicas. Brasília, DF: IPEA.

Mahoney, J., Schensul, D. (2006). Historical context and path dependence. In: Box, C., Stokes, S. C. The Oxford handbook of comparative politics. New York: Oxford University Press Inc. 
Ricardo Dias Ramagem, et al. Construção de capacidades político-relacionais para coordenação feder...

Mann, M. (2008). Infrastructural Power Revisited. Studies in Comparative International Development (SCID), 43(3), 355-365.

Matthews, F. (2012). Governance and State Capacity. In Levi-Faur, David, ed. The Oxford Handbook of Governance. Oxford University Press, 281-293 pp.

Midlej, S. (2013). Democracia participativa e processo decisório de políticas públicas: a influência da campanha contra a Alca. Revista Sociedade e Estado, 28(1), 53-74.

Miles, M. B., Huberman, A. M. (1994). Qualitative Data Analysis: An Expanded Sourcebook. 2 ed. Thousand Oaks, CA: Sage Publications, 336 pp.

O Brasil sem miséria. Campello, T., Falcão, T., Costa, P. (org.). Brasília-DF, Ministério do Desenvolvimento Social e Combate à Fome.

OECD (2013). OECD Territorial Reviews: Brazil 2013. OECD Publishing.

Plano Plurianual [PPA] 2012-2015. Brasília, 278 p. Cadernos de Estudos Desenvolvimento Social em Debate. N. 7. Programa Cisternas. Brasília, DF, Brasil.

Oliveira, V. E., Lotta, G. (2017). De qual burocracia as políticas públicas intersetoriais e federativas precisam? Análise das competências requeridas à atuação dos gestores do programa Bolsa Família - Cadernos 50, 72p. Brasília, DF: Enap.

Perez, M. A. (2009). Administração Pública Democrática: institutos de participação popular na administração pública. Belo Horizonte: Forum. Cap. 4, p. 71-85.

Pierson, P. (2004). Politics in time: history, institutions, and social analysis. Princeton: Princeton University Press.

Pires, R. R. C., Gomide, A. A. (2016). Governança e Capacidades Estatais: uma análise comparativa de programas federais. Revista de Sociologia e Politica, 24(58), 121-143.

Pires, R., Vaz, A. (2014). Para além da participação: interfaces socioestatais no governo federal. Lua Nova, 93(1), 61-91.

Política Nacional de Desenvolvimento Regional [PNDR]. Avaliação da política nacional de desenvolvimento regional. Brasília, DF: Brasil.

Sotero, E. M., Lotta, G. S., Oliveira. E. M. M. (2019). O Programa "De Braços Abertos": Um olhar à luz dos seus arranjos institucionais. Administração Pública e Gestão Social, 11(3), 1-17.

Thelen, K., Steinmo, S. (1992). Historical institutionalism in comparative politics. In Steinmo, S., Thelen, K., Longstreth, F. (Eds.). Structuring Politics: Historical Institutionalism in Comparative Analysis, pp. 1-32. Cambridge: Cambridge University Press.

Thelen, K. (1999). Historical institutionalism in comparative politics. Annual Review of Political Science, 2(1), 369-404.

Veiga, L., Bronzo, C. (2014). Estratégias intersetoriais de gestão municipal de serviços de proteção social: a experiência de Belo Horizonte. Revista de Administração Pública, 48(3), 595-620.

Wu, X., Ramesh, M., Howlett, M. (2015). Policy Capacity: A conceptual framework for understanding policy competences and capabilities. Policy and Society, 34(1), 165-171.

Yin, R. K. (2014). Estudo de caso: planejamento e métodos. 4 ed. Porto Alegre: Bookman. 